\title{
Assessment of exposure to polycyclic aromatic hydrocarbons in engine rooms by measurement of urinary 1-hydroxypyrene
}

Bente E Moen, Ralph Nilsson, Rolf Nordlinder, Steinar Øvrebø, Kristin Bleie, Anne Helene Skorve, Bjørg Eli Hollund

\begin{abstract}
Objective-Machinists have an increased risk of lung cancer and bladder cancer, and this may be caused by exposure to carcinogenic compounds such as asbestos and polycyclic aromatic hydrocarbons (PAHs) in the engine room. The aim of this study was to investigate the exposure of engine room personnel to PAHs, with 1-hydroxypyrene in urine as a biomarker.

Methods-Urine samples from engine room personnel $(n=51)$ on 10 ships arriving in different harbours were collected, as well as urine samples from a similar number of unexposed controls $(n=47)$ on the same ships. Urinary 1-hydroxypyrene was quantitatively measured by high performance liquid chromatography. The exposure to PAHs was estimated by a questionnaire answered by the engine room personnel. On two ships, air monitoring of PAHs in the engine room was performed at sea. Both personal monitoring and area monitoring were performed. The compounds were analysed by gas chromatography of two types (with a flame ionisation detector and with a mass spectrometer).
\end{abstract}

Results-Significantly more 1-hydroxypyrene was found in urine of personnel who had been working in the engine room for the past 24 hours, than in that of the unexposed seamen. The highest concentrations of 1-hydroxypyrene were found among engine room personnel who had experienced oil contamination of the skin during their work in the engine room. Stepwise logistic regression analysis showed a significant relation between the concentrations of 1-hydroxypyrene, smoking, and estimated exposure to PAHs. No PAHs were detected in the air samples.

Conclusion-Engine room personnel who experience skin exposure to oil and oil products are exposed to PAHs during their work. This indicates that dermal uptake of PAHs is the major route of exposure.

(Occup Environ Med 1996;53:692-696)

Keywords: engine room; 1-hydroxypyrene; polycyclic aromatic hydrocarbons

Several epidemiological studies have shown an increased risk of both lung cancer and bladder cancer among machinists compared with the general population. ${ }^{1-7}$ This increased risk may be due to smoking, but occupational factors have been suggested as additional aetiological factors. A known occupational carcinogenic factor in engine rooms is asbestos, as several ships have used this type of insulation material. This is hardly a problem today, as other types of insulation material are used. ${ }^{8}$ Other possible carcinogenic factors are polycyclic aromatic hydrocarbons (PAHs). Exposure to these compounds may occur during work with oil and oil products in the engine rooms. Fuels used in marine engines can differ greatly in content of PAHs, depending on the origin and contamination of the fuel. ${ }^{9}$ Several fuel oils are known to have high concentrations of these compounds. ${ }^{10}$ PAHs can also be formed during combustion in the engine room, and arise from exhaust gases and soot. ${ }^{11}$ Exhaust gases may also contain nitroarenes. ${ }^{11}$ Several individual PAHs have been shown to have carcinogenic or mutagenic activity, or both, ${ }^{12}$ and these compounds may be related to the increased risk of both lung and bladder cancer. ${ }^{12-14}$ The risk of cancer associated with work as a machinist may therefore be related to occupational exposure to PAHs in the engine room. Exposure to fuel oils and combustion products probably takes place in engine rooms even today. Therefore, it is of interest to evaluate the present exposure to PAHs.

Polycyclic aromatic hydrocarbons are metabolised to many different compounds. ${ }^{15}$ Most of these are excreted in the faeces and only a minor fraction is excreted in the urine. Pyrene, however, is almost completely metabolised to 1-hydroxypyrene and conjugates, which are excreted in the urine. ${ }^{16}$ The content of pyrene is often high in PAH mixtures, ${ }^{17}$ and 1-hydroxypyrene has been used as a variable for the biological monitoring of exposure to compounds containing PAHs. ${ }^{18-19}$ Exposure to PAHs may occur by inhalation, by dermal exposure, and by oral uptake. ${ }^{15}$ Considerable variation between people has been found in the peak urinary excretion of 1hydroxypyrene after exposure to compounds containing PAHs, with a mean (range) of 10.4 (3.9-26.7) hours. ${ }^{17}$ This makes the exposure to compounds containing PAHs in the past 24 hours relevant to the urinary analysis of this metabolite.

Data on exposure to compounds containing PAHs in engine rooms are scarce. This study was performed to evaluate the exposure to PAHs among engine room personnel on ships today, and the need for improvement of their working environment to reduce this type of chemical hazard.
University of Bergen, Norway.

Accepted 10 May 1996 


\section{Material and methods}

SELECTION OF SHIPS AND THE STUDY POPULATION

The engine rooms on ships and the working conditions for the personnel in these rooms may differ. In earlier days, the engine room was built as one single room with the engines, the separators, and a small workshop. The engine room crew spent most of their working hours inside this room. In ships built today, the engine room is often divided into different rooms; rooms for the engines, separator room, workshop, and control room. The crew spend most of their working hours in the control room.

Ten ships, five arriving in a large Norwegian harbour, four arriving in a large harbour in Sweden, and one during maintenance work at a shipyard in France, were chosen for the present study. There were five passenger ships, two roll on roll off ships, two product tankers, and a container ship. The ships were built between 1956 and 1993 and the size ranged from 5000 to 50000 dead weight tonnes.

Four of the ships were chosen because they were old, with a engine room without a separate control room. The other ships were chosen at random. All ships were visited on randomly selected days. We asked for permission to visit the ships and collect the samples shortly before the ships arrived in the harbour.

All the engine room personnel on the ships were included in the study. A control group was established by including a similar number of men from the crew on each ship who did not work with oil, oil products, or other sources of exposure to PAHs. Nobody refused to participate in the study.

\section{SAMPLING OF URINE AND ANALYSIS OF 1-HYDROXYPYRENE}

Each participant of the study answered a questionnaire with questions about age, occupation, exposure to possible sources of $\mathrm{PAH}$ the past 24 hours, use of gloves, overalls, and personal respiratory protection equipment. Participants also answered questions about smoking habits, as tobacco smoke may influence the results. ${ }^{20}$ Also, 1-hydroxypyrene may be increased by the intake of food rich in PAHs. ${ }^{2021}$ However, as the personnel from the engine room and the control group had the same food on the ships, the diet was unlikely to influence the results to any large extent. Therefore, no questions concerning the diet were included in the questionnaire.

A sample of urine $(50 \mathrm{ml})$ was obtained from each person. The samples were immediately frozen at $-20^{\circ} \mathrm{C}$ and remained so until laboratory analysis of the urine. Each sample was coded and analysed without knowledge of the person's name and exposure status. The method used for measurement of 1-hydroxypyrene in urine was that described by Jongeneelen. ${ }^{22}$ Urine $(10 \mathrm{ml})$ was diluted with acetic acid, the $\mathrm{pH}$ adjusted, and incubated for 16 hours after addition of an enzyme mix of glucuronidase and sulphatase. This mixture was applied on a Sep-pak $\mathrm{C}_{18}$ cartridge (Millipore, Milford, MA) The cartridges were washed with water and eluted with $4 \mathrm{ml}$ methanol. The eluate $(20 \mu \mathrm{l})$ was injected into a high performance liquid chromatograph with a Novapak $\mathrm{C}_{18}$ column. The elution was with a methanol/water gradient and detection with a fluorescence detector (Perkin-Elmer, Beaconsfield, UK) at $242 \mathrm{~nm}$ (excitation) and a $288 \mathrm{~nm}$ (emission). Five spiked control urine samples were used as standards with addition of $10,20,40,100$, and $250 \mathrm{nmol} / 1$-hydroxypyrene (Jansen Chimica, Beerse, Belgium). Measurement was performed with Millennium integration software. All measurements were corrected for creatinine.

PAHS IN WORKROOM AIR

The concentrations of PAHs in the engine rooms on two different passenger ships were monitored. In one of the ships, built in 1956, the engine room consisted of a single room where both the engines and the engine room crew were located. The other ship, built in 1993, had a control room where the crew was located most of the time. The monitoring of PAHs was performed during two similar sea voyages along the Norwegian coast.

Engine room personnel on duty during the voyage were monitored for PAHs. Area monitoring was carried out at a minimum of two positions in each engine room, at places were PAH exposure was likely to occur and where the engine room crew used to stay during their work. The sampling was performed for two or three working shifts. The compounds containing PAHs (both gasous and particulate phases) were collected on an acrylic copolymer filter (Versapor 800, Gelman Sciences, Ann Arbor, Michigan) and XAD-2 in series. Medium flow pumps (DuPont $a-1$ and DuPont P/S 2500, DuPont, Largo, Florida and Casella AFC 123IS, Casella, London, England) maintained at a flow rate of $21 / \mathrm{min}$ were used for the sampling.

The compounds containing PAHs were extracted from XAD-2 with dichloromethane after addition of internal standards. The filters were extracted with cyclohexane in an ultrasonic bath after addition on internal standards. Polar compounds and PAHs were transferred to $\mathrm{N}, \mathrm{N}$-dimethylformamide with $3 \%$ water. After dilution with water, the PAHs were extracted back into cyclohexane. The extracts were dried with water free $\mathrm{Na}_{2} \mathrm{SO}_{4}$ and concentrated. Both types of extracts were analysed splitless on an HP 5890 series II gas chromatograph with flame ionisation detector. The column used was a $25 \mathrm{~m} \mathrm{CP-sil-8} \mathrm{CB} \mathrm{(inner}$ diameter, $0.25 \mathrm{~mm}$; film thickness, $0.25 \mu \mathrm{m}$ ) and the oven was programmed from 35 to $310^{\circ} \mathrm{C}$, with a run time of 90 minutes. Table 1 shows the analysed components. The detection limit was $13.6 \mathrm{ng} / \mathrm{m}^{3}$ for pyrene and $10 \mathrm{ng} / \mathrm{m}^{3}$ for benzo[a]pyrene $\left(0.4 \mathrm{~m}^{3}\right.$ air sample). All of the analysed components had a detection limit $<1 \mu \mathrm{g} / \mathrm{m}^{3}$ ( $1 \mathrm{~m}^{3}$ sample).

\section{STATISTICAL METHODS}

For categorical data, $\chi^{2}$ tests were performed to compare groups. For continuous data, nonparametric tests were used, as the data were not normally distributed. An arbitrary cut off point 
Table 1 Polycyclic aromatic hydrocarbons and other polycyclic organic compounds analysed in a study of the working environment in the engine room of two ships

\begin{tabular}{rlll}
\hline 1 & Naphthalene & 23 & 1-Methylphenanthrene \\
2 & 2-Methylnaphthalene & 24 & 9-Methylanthracene \\
3 & 1-Methylnaphthalene & 25 & Fluoranthene \\
4 & Biphenyl & 26 & Pyrene \\
5 & Acenaphthylene & 27 & Benzo[a] fluorene \\
6 & Acenaphthene & 28 & Benzo[b]fluorene \\
7 & Dibenzofuran & 29 & 1-Methylpyrene \\
8 & Fluorene & 30 & Benz[a]anthracene \\
9 & 9-Methylfluorene & 31 & Chrysene \\
10 & 9,10-Dihydroanthracen & 32 & Benzo[b]fluoranthene \\
11 & 2-Methylfluorene & 33 & Benzo[k]fluoranthene \\
12 & 1-Methylfluorene & 34 & Benzo[a]pyrene \\
13 & Dibenzothiophene & 35 & Benzo[e]pyrene \\
14 & Phenanthrene & 36 & Perylene \\
15 & Anthracene & 37 & Indeno[1,2,3-cd]pyrene \\
16 & Acridine & 38 & Dibenz[a,c]anthracene \\
17 & Benzo[f]quinoline & 39 & Benzo[ghi]perylene \\
18 & Carbazole & 40 & Anthanthrene \\
19 & 3-Methylphenanthrene & 41 & Dibenzo[a,e]pyrene \\
20 & 2-Methylphenanthrene & 42 & Coronene \\
21 & 2-Methylanthracene & 43 & Dibenzo[a,i]pyrene \\
22 & 4,5-Methylenphenanthrene & 44 & Dibenzo[a,h]pyrene \\
\hline
\end{tabular}

for 1-hydroxypyrene $(0 \cdot 2 \mu \mathrm{mol} / \mathrm{mol}$ creatinine) was chosen and a stepwise logistic regression analysis was chosen to evaluate the relation between 1-hydroxypyrene, exposure, smoking, and age.

The exposure of the crew to PAHs was categorised according to their answers on the questionnaire. The categories were unexposed, meaning no known exposure to PAHs in the past 24 hours, exposed degree I, meaning that they had been working inside the engine room during the past 24 hours; and exposed degree II, meaning that they had been working in the engine room during the past 24 hours and had experienced contamination of the skin with oil during this period.

\section{Results}

MONITORING OF URINE

A total of 98 samples of urine were collected, 51 from personnel who had been working in the engine room and 47 from a control group on the same ships who had not been exposed to compounds containing PAHs in the engine room. The crew were working for periods of four or six weeks on the ship, and in shifts of four or six hours.

The control group was older than both the exposed groups (exposed degree I and exposed degree II: Mann-Whitney rank sum test, $\mathbf{P}=$ $0 \cdot 02$ ). No significant difference was found between the groups for smoking habits (table 2; $\chi^{2}$ test, $P=0.4$ )

None of the engine room personnel had used

Box plot of the

concentrations of 1 -

hydroxypyrene in urine of different groups of seamen, related to smoking habits and estimated exposure to compounds containing $P A H s$ during work. $A=$ unexposed non-smokers (n $=27$ );

$B=$ degree $I$ exposed nonsmokers $(n=10) ; C=$ degree II exposed nonsmokers $(n=15) ; D=$ unexposed smokers $(n=$ $20) ; E=$ degree I exposed $20) ; E=$ degree $I$ (expo
smokers $(n=17)$ $F=$ degree II exposed smokers $(n=9)$.

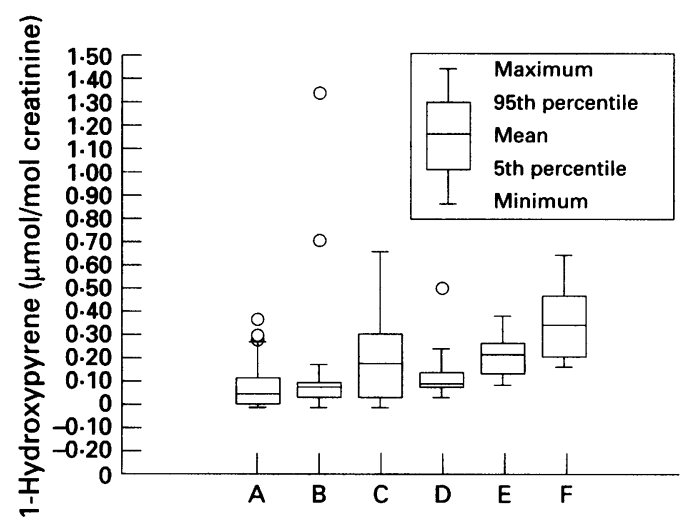

personal respiratory protection equipment in the past 24 hours. Two people had used gloves for a short period during work with oil and grease in a motor, but they had not used gloves all the time during this work. All but two people had used overalls during the work.

A significantly higher urinary concentration of the PAH metabolite 1-hydroxypyrene was found among personnel who had been working in the engine room during the past 24 hours (exposed groups, degrees I and II), compared with unexposed personnel on the ships (MannWhitney rank sum test, $P<0.0001)$. As smoking may interfere with the results, a comparison of exposed (both degree I and degree II) and unexposed non-smokers was performed as well, showing a similar difference (Mann-Whitney rank sum test, $P=0.02$ ). Comparing nonsmokers of degree I with non-smokers of degree II, a significant difference was found between the groups (Mann-Whitney rank sum test, $P=$ $0.04)$. No significant difference was found between the urinary concentrations of 1hydroxypyrene in the unexposed non-smokers and those of the non-smokers in the exposed group, degree I, (Mann-Whitney rank sum test, $P=0.72$ ). The urinary concentrations of 1hydroxypyrene in the non-smokers of the unexposed group were significantly lower than those of the non-smokers in the exposed group, degree II, (Mann-Whitney rank sum test, $\mathrm{P}=$ 0.01 ). The figure shows the concentrations of 1-hydroxypyrene in the different groups.

Significant relations between the concentration of 1-hydroxypyrene (cut off point set to $0 \cdot 2$ $\mu \mathrm{mol} / \mathrm{mol}$ creatinine) and both exposure $(P<0.001)$ and smoking $(P<0.001)$ were found by a stepwise logistic regression analysis. No significant relation between age and 1-hydroxypyrene was found ( $P=0 \cdot 8)$.

The urinary concentrations of 1-hydroxypyrene of both smokers and non-smokers among the exposed personnel on the old ships were not significantly different from those of the exposed personnel on the new ships. Also, no significant difference was found between the non-smokers in these groups.

\section{AIR MONITORING}

Air monitoring was performed on two passenger ships, built in 1956 and 1993. Table 3 shows the information about the ships and the work performed in the engine rooms during the monitoring period.

Altogether 19 samples were collected. For each series (each ship), there was one blank. Three of the samples were destroyed by a technical failure, giving a total number of 16

Table 2 Smoking habits among engine room crew occupationally exposed to compounds containing PAHs and a control group

\begin{tabular}{llc}
\hline Smoking habits & $\begin{array}{l}\text { No exposure } \\
\text { to } P A H s \\
(n=47)\end{array}$ & $\begin{array}{l}\text { Exposure } \\
\text { to PAHs } \\
(n=51)\end{array}$ \\
\hline $\begin{array}{l}\text { Non-smokers } \\
\text { Cigarettes/day : }\end{array}$ & 27 & 25 \\
$1-5$ & 4 & 2 \\
$6-10$ & 2 & 8 \\
$11-20$ & 9 & 10 \\
$>20$ & 5 & 6 \\
\hline
\end{tabular}


Table 3 Description of two Norwegian passenger ships and their engine rooms where air monitoring of compounds containing PAHs was performed

\begin{tabular}{|c|c|c|}
\hline & Ship $A$ & Ship B \\
\hline Date built & 1956 & 1993 \\
\hline Gross tonnage & 2200 & 11200 \\
\hline Engines & $\begin{array}{l}1 \text { main engine } \\
3 \text { auxiliary engines }\end{array}$ & $\begin{array}{l}2 \text { main engines } \\
2 \text { auxiliary engines }\end{array}$ \\
\hline Control room & No control room & $\begin{array}{l}\text { A special control room } \\
\text { that housed the engine crew } \\
\text { most of the time }\end{array}$ \\
\hline Room for separators & No & Yes \\
\hline Fuel & Marine special distillate (MSD) & Marine special distillate (MSD) \\
\hline $\begin{array}{l}\text { Work performed by } \\
\text { the engine crew }\end{array}$ & $\begin{array}{l}\text { Maintenance work performed } \\
\text { by a mechanic and } \\
\text { machinist during the } \\
\text { first shift. During the } \\
\text { second shift some cleaning } \\
\text { with white spirit was performed }\end{array}$ & $\begin{array}{l}\text { Surveillance - mainly from } \\
\text { the control room. Few and } \\
\text { short visits in the engine room }\end{array}$ \\
\hline
\end{tabular}

analysed samples. Nine of these samples were stationary, and seven were personal samples. The sampling period was restricted to six hours, as this was the duration of the workshifts on board. No PAHs were detected in any of the samples.

\section{Discussion}

This study shows a significant relation between an estimated exposure to PAHs during work in the engine rooms of ships and the concentration of the $\mathrm{PAH}$ metabolite 1-hydroxypyrene in urine. The excretion of 1hydroxypyrene was significantly increased in a group of engine room personnel who had experienced dermal exposure to oil products compared with a group of unexposed seamen. Estimation of the exposure was based on self observed exposure to the skin and probable inhalation of the PAHs during work with oil and oil products in the engine rooms. Monitoring of PAHs in the air of the engine rooms did not show any such compounds present. This suggests that the engine room crew receive their exposure to compounds containing PAHs mostly by dermal contamination, and less by inhalation. Oil contamination of the skin during special types of work seems to cause the major exposure to compounds containing PAHs in the engine rooms.

Standardised and established methods were used for the sampling and analyses of 1-hydroxypyrene, ${ }^{22}$ and methodological errors are unlikely in the present study.

The temperature in engine rooms may be high, and it is probable that this may affect the urinary concentration of the personnel working in the engine room. This may influence the concentration of the urinary metabolite, but was corrected, as the concentration of 1hydroxypyrene was adjusted for creatinine.

Several factors are known to influence urinary concentrations of 1-hydroxypyrene. Our results confirm the importance of cigarette smoking. The relation between smoking and urinary concentrations of 1-hydroxypyrene has been shown in several studies. ${ }^{20} 23$ Age in our study was not found to have any relation with the concentration of urinary 1-hydroxypyrene. This effect has been suggested, ${ }^{24}{ }^{25}$ but no significant relations have been found.

The ships included in this study were chosen with no previous knowledge about the engine room or the exposures to compounds containing PAHs. All shipowners asked allowed their ships to participate in the study. The information obtained should therefore be without any bias from shipowners or crew.

The overall values of 1-hydroxypyrene found in this study were lower than those found in other occupational groups with exposure to compounds containing PAHs. Workers exposed to creosote have been shown to have concentrations of 1-hydroxypyrene up to $84 \mu \mathrm{mol} / \mathrm{mol}$ creatinine, and coke oven workers up to $11 \mu \mathrm{mol} / \mathrm{mol}$ creatinine. ${ }^{1823}$ However, our data are similar to values found among car repair workers. ${ }^{26}$ The exposure of this type of worker is more comparable with personnel from engine rooms than the exposure of creosote workers or coke oven workers. Both automobile repair workers and personnel from engine rooms perform mechanical repair work, and are known to experience skin contamination by oil and oil products during this work. They may be exposed to compounds containing PAHs by dermal exposure, as well as by inhalation of oil mist or combustion products. The types of compounds containing PAHs present in the environment of car mechanics may also be more similar to those found in the engine rooms than in the environment of creosote workers and coke oven workers.

The concentrations of 1-hydroxypyrene found in the present control group was similar to the values found in unexposed groups from other studies. The control group in the study of car repair workers showed a mean concentration of hydroxypyrene of $0.08 \mu \mathrm{mol} / \mathrm{mol}$ creatinine among non-smokers and of $0.16 \mu \mathrm{mol} / \mathrm{mol}$ creatinine among smokers. ${ }^{26}$ In our study, equivalent values were 0.09 and 0.14 . In a Canadian study of urinary 1-hydroxypyrene in non-occupationally exposed people, equivalent values were 0.07 and $0.12 \mu \mathrm{mol} / \mathrm{mol}$ creatinine. ${ }^{25}$ A Danish study showed a mean concentration of urinary 1-hydroxypyrene of $0.012 \mu \mathrm{mol} / \mathrm{mol}$ creatinine in a population with no occupational exposure to compounds containing PAHs. ${ }^{27}$

To our knowledge, there are no previously published studies of the exposure to compounds containing PAHs in engine rooms. However, monitoring of occupational exposure has been performed in Finland, ${ }^{28}$ and the researchers have described the exposures to compounds containing PAHs as low. A Norwegian study reports similar information. ${ }^{29}$ In that study only traces of PAHs were detected in the air of the engine rooms, although these compounds were shown to be present in the fuel and oil products used in the engine room environment. This supports our findings, with almost no compounds containing PAHs present in the air, not even during maintenance work with visible oil spilt in the working area. On the other hand, the engine room personnel may sometimes perform other types of work which may cause exposure to compounds containing PAHs in the air. These types of work have not been monitored in the present study.

The monitoring periods of the air samples were short, due to the duration of the shifts. 
Sampling periods less than eight hours are not unusual in occupational settings, as special working periods may have varying durations. ${ }^{3131}$ Short sampling periods may reduce the chance of finding components in the air. However, the risk of not detecting PAHs in the air of the engine room was reduced in this study by the low detection limits of the PAHs.

Although several compounds containing PAHs are classified as carcinogenic, ${ }^{1012}$ it is difficult to evaluate the health risk connected to the concentrations of 1-hydroxypyrene found among personnel working in engine rooms. Little knowledge exists as to what concentration compounds containing PAHs actually will cause cancer. However, as exposure to compounds containing PAHs seems to be present in this occupational environment, a small increased risk of developing occupational cancer may be present. It is wise to reduce the present exposure as much as possible. This can probably be done easily in the engine rooms, by reducing the dermal exposure to oil and oil products by improved protection of the skin.

\section{Conclusion}

Seamen who had been working in the engine room for the past 24 hours, had a significantly higher concentration of 1-hydroxypyrene in the urine than unexposed seamen. The highest concentrations of 1-hydroxypyrene were found among engine room personnel who had experienced oil contamination of the skin during their work in the engine room. No PAHs were detected in air samples from the engine rooms. As oil contamination of the skin is known to be a possible source of exposure to PAHs, the results indicate that dermal uptake of PAHs may occur during work in engine rooms.

This study was supported by the Norwegian Shipowners Association, the Norwegian Petroleum Institute, the Norwegian Mates' Association, the Council for Labour Supervision on Norwegian Ships, and the Swedish Work Environment Fund. Sincere thanks are also expressed to Hilde Noto at the laboratory Sincere thanks are also expressed to Hilde Noto at the laboratory
at The National Institute of Occupational Health, Oslo and at The National Institute of Occupational Health, Oslo and
Gerd Granung at the Department of Occupational Medicine, Sahlgrenska University Hospital, Göteborg. The technical assistance of An Deverill was appreciated.

1 Dubrow R, Wegman DH. Cancer and occupation in Massachusetts: a death certificate study. Am $\mathcal{f}$ Ind Med 1984;6:207-30

2 Malker HSR, McLaughlin JK, Silverman DT, Ericsson JLE, Stone BJ, Weiner JA, et al. Occupational risks for bladder cancer among men in Sweden. Cancer Res 1987; cancer an

3 Tola S, Tenho M, Korkala M-L, Järvinen E. Cancer of the urinary bladder in Finland. Int Arch Occup Environ Health 1980;46:43 51

4 Silverman DT, Levin LI, Hoover RN, Hartge P. Occupational risks of bladder cancer in the United States. Natl Cancer Inst 1989;81:1472-80.

5 Dolin PJ, Cook-Mozaffari P. Occupation and bladder cancer. Br f Cancer 1992;66:568-78.

6 Howe GR, Burch JD, Miller AB, Cook GM, Esteve J, Morrison B, et al. Tobacco use, occupation, coffee, various nutritients and bladder cancer. F Natl Cancer Inst 1980;64: 701-13.

7 Wynder EL, Goldsmith R. The epidemiology of bladder cancer. Cancer 1977;40:1246-68.

8 Rapiti E, Turi E, Forastiere F, Borgia P, Comba P, Perucci CA, Axelson O. A mortality cohort study of seamen in Italy. Am f Ind Med 1992;21:863-72.

9 International Agency for Research on Cancer. IARC monographs on the evaluation of carcinogenic risks to humans. polynuclear aromatic compounds, part 2. Carbon black, mineral oils and some nitroarenes. Vol 33. Lyon: IARC,
1984:93-7.
10 International Agency for Research on Cancer. IARC Monographs on the evaluation of carcinogenic risks to humans: occupational exposures in petroleum refining; crude oil and major petroleum fuels. Vol 45. Lyon: IARC, 1989:239 49

11 International Agency for Research on Cancer. IARC monographs on the evaluation of carcinogenic risks to humans: diese and gasoline, engine exhausts, and some mitroarenes. Vol 46. Lyon: IARC, 1989:47-58.

12 International Agency for Research on Cancer. IARC monographs on the evaluation of carcinogenic risks to humans: polynuclear aromatic compounds. Part 1: chemical, environmental and experimental data. Vol 33. I.yon: IARC, 1984 95447 .

13 Jongeneelen F. Biological monitoring of occupational exposure to polycyclic aromatic hydrocarbons [thesis] Nijmegen: Scientific Publishers, 1987

14 Tremblay C, Armstrong B, Thériault G, Brodeur J. Estimation of risk of developing bladder cancer among worker exposed to coal tar pitch volatiles in the primary aluminium industry. Am $\mathcal{F}$ Ind Med 1995;27:335 48

15 Becher G, Bjørseth A. Determination of occupational exposure to PAH by analysis of body fluids. In: Bjorseth A Ramdahl T, eds. Handbook of polycyclic aromatic hydrocarbons. Vol 2. New York: Marcel Dekker, 1985, 237-52.

16 Jongeneelen FJ, Bos RP, Anzion RBM, Theuws JLG, Henderson PT. Biological monitoring of polycyclic aromatic hydrocarbons; metabolites in urine. Scand f Work Environ Health 1986;12:137-43.

17 Boogaard PJ, van Sittert NJ. Exposure to polycyclic aromatic hydrocarbons in petrochemical industries by measurements of urinary 1-hydroxypyrene. Occup Environ Med 1994;51:250-8

18 Tolos WP, Shaw PB, Lowry LK, MacKenzie BA, Deng J-F 1-Pyrenol: a biomarker for occupational exposure to polycyclic aromatic hydrocarbons. Appl Occup Environ Hy 1990;5:303-9.

19 Buchet JP, Gennart JP, Mercado-Calderon F, Delavignette JP, Cupers L, Lauwerys R. Evaluation of exposure to polycyclic aromatic hydrocarbons in a coke production and a graphite electrode manufacturing plant: assessment of urigraphite electrode manufacturing plant: assessment of urinary excretion of 1-hydroxypyrene as a bio
of exposure. Br f Ind Med 1992;49:761-8.

20 Van Rooij JG, Veeger MM, Bodelier-Bade MM, Scheper PT, Jongeneelen FJ. Smoking and dietary intake of poycyclic aromatic hydrocarbons as sources of interindividua variability in the baseline excretion of 1-hydroxypyrene in urine. Int Arch Occup Environ Health 1994;66:55 65.

21 Buckley TJ, Lioy PJ. An examination of the time course from human dietary exposure to polycyclic aromatic hydrocarbons to urinary elimination of 1-hydroxypyrene. $\mathrm{Br} F$ Ind Med 1992;49:113-24.

22 Jongeneelen FJ, Anzion RBM, Henderson PT. Determination of hydroxylated metabolites of polycyclic aromatic hydrocarbons in urine. $f$ Chromatogr 1987;413: 227-32.

23 Jongeneelen FJ, Anzion RBM, Scheepers PTJ, Bos RP, Henderson PT, Nijenhuis EH. 1-hydroxypyrene in urine as a biological indicator of exposure to polycyclic aromatic hydrocarbons in several work environments. Ann Occup Hyg 1988;32:35-43.

24 Van Rooij JGM, Bodelier-Bade MM, Hopmans PMJ, Jongeneelen FJ. Reduction of urinary 1-hydroxypyrene excretion in coke-oven workers exposed to polycyclic aromatic hydrocarbons due to improved hygienic skin protecmatic hydrocarbons due to improved hygienic skin

25 Viau C, Vyskocil A, Martel L. Background urinary 1 hydroxypyrene levels in non-occupationally exposed individuals in the Province of Québec, Canada, and comparison with its excretion in workers exposed to PAH mixtures. Sci Total Environ 1995;163:191-4.

26 Granella M, Clonfero E. Urinary excretion of 1-pyrenol in automotive repair workers. Int Arch Occup Environ Health 1993;65:241-5

27 Hansen AM, Christensen JM, Sherson D. Estimation of reference values for urinary 1-hydroxypyrene and $\beta$-naphthol in Danish workers. Sci Total Environ 1995;163. 211-n.

28 Minni E, Nikkilä A, Hakala E. Polycyclic aromatic hydrocarbons on ships. In: Abstracts from the 36th Nordic Meeting on Occupational Health, Administration of Occupational Safety and Health Reykjavik: 1987:135 -6.

29 Mulige helseproblemer ved bruk av brennoljer. Oslo: Norwegian Shipowners Association, 1987. (In Norwegian.)

30 Omland $\varnothing$, Sherson D, Hansen ÅM, Sigsgaard T, Autrup $\mathrm{H}$, Overgaard E. Exposure of iron foundry workers to polycyclic aromatic hydrocarbons: benzo(a)pyrene-albumin adducts and 1-hydroxypyrene as biomarkers for exposure. Occup Environ Med 1994;51:513-8.

31 Hansen $\AA$ M, Omland $\emptyset$, Poulsen OM, Sherson D, Sigsgaard T, Christensen JM, Overgaard E. Correlation between work process-related exposure to polycyclic aromatic hydrocarbons and urinary levels of $\alpha$-naphthol $\beta$-naphthylamine and 1-hydroxypyrene in iron foundry $\beta$-naphthylamine and 1-hydroxypyrene in iron foundry
workers. Int Arch Occup Environ Health 1994;65. workers.

32 Van Rooij JGM, Van Lieshout EMA, Bodelier-Bade MM, Jongeneelen FJ. Effect of the reduction of skin contamination on the internal dose of creosote workers exposed to polycyclic aromatic hydrocarbons. Scand 7 Work Environ Health 1993;19:200-7. 